\title{
Conjuntura e desafios políticos: O que sabemos sobre o estado de nossa democracia no Brasil e o que nos dizem os jovens?
}

Dantas, Humberto; Carvalho Teixeira, Marco Antônio

Conjuntura e desafios políticos: O que sabemos sobre o estado de nossa democracia no Brasil e o que nos dizem os jovens?

Administração Pública e Gestão Social, vol. 12, núm. 3, 2020

Universidade Federal de Viçosa, Brasil

Disponible en: http://www.redalyc.org/articulo.oa?id=351563312016

Esta obra está bajo una Licencia Creative Commons Atribución-NoComercial-SinDerivar 3.0 Internacional. 


\title{
Conjuntura e desafios políticos: O que sabemos sobre o estado de nossa democracia no Brasil e o que nos dizem os jovens?
}

\author{
Political conjuncture and challenges: What do we know about our democracy in Brazil, and how does youth feel \\ about it? \\ Coyuntura y desafíos políticos: ¿Que sabemos sobre el estado de nuestra democracia y que piensan los jóvenes acerca \\ de eso?
}

Humberto Dantas

Escola de Administração de Empresas da Fundação Getulio

Redalyc: http://www.redalyc.org/articulo.oa?

Vargas de São Paulo, Brasil

humbertodantasneto@gmail.com

Marco Antônio Carvalho Teixeira

Escola de Administração de Empresas da Fundação Getulio

Vargas de São Paulo, Brasil

marco.teixeira@fgv.br id $=351563312016$

\author{
Recepción: 09 Enero 2020 \\ Aprobación: 09 Enero 2020 \\ Publicación: 01 Julio 2020
}

\section{Resumo:}

O adensamento de movimentos populares pelo mundo nas últimas décadas, demonstrando insatisfação com situações de ordem pública é o resultado de mais democracia ou a incapacidade de o Estado democrático se fazer presente? No Brasil, em que instante se está da democracia? O objetivo deste texto é compreender o momento político atual, buscando observar como o brasileiro avalia a democracia. A partir disso, o que jovens de ensino médio de escolas públicas da Grande São Paulo poderiam dizer sobre essa temática? Eis o que existe de inédito neste texto: A avaliação, de cinco anos, da percepção de tais estudantes, colhida por meio da aplicação de questionários fechados. Será possível notar resultados positivos e negativos capazes de subsidiar debates relevantes sobre a realidade, partindo da hipótese de que existe uma mudança em curso na percepção de parcelas pesquisadas da sociedade sobre o sentido da política e da democracia.

Palavras-Chave: Democracia, movimentos sociais, conjuntura política, juventude, educação política..

\section{Abstract:}

Is the thickening of popular movements around the world in recent decades, showing dissatisfaction with public order situations, the result of more democracy? Or is it the inability of the democratic state to be present? In Brazil, what is the moment of democracy? The purpose of this text is to understand the current political moment, seeking to observe how the Brazilian population evaluates democracy. From this, what could high school youth from public schools in the Metropolitan Area of São Paulo say about this theme? Here is what is unheard of in this text: The five-year assessment of the perception of such students collected through the application of closed questionnaires. It will be possible to see positive and negative results capable of subsidizing relevant debates about reality, assuming that there is an ongoing change in the perception of researched portions of society about the meaning of politics and democracy.

KEYWORDS: Democracy, social movements, political conjuncture, youth, political education.

\section{Resumen:}

¿El carácter denso de los movimientos populares en todo el mundo en las últimas décadas, que muestra insatisfacción con las situaciones de orden público, es el resultado de una mayor democracia o la incapacidad del estado democrático para estar presente? En Brasil, ¿cuál es el momento de la democracia? El propósito de este texto es comprender el momento político actual, buscando observar cómo el pueblo brasileño evalúa la democracia. A partir de esto, ¿qué podrían decir los jóvenes de secundaria de las escuelas públicas del Área Metropolitana de São Paulo sobre este tema? Esto es lo que tenemos de inédito en este texto: La evaluación de cinco años de la percepción de tales estudiantes recopilada mediante la aplicación de cuestionarios cerrados. Será posible ver 
resultados positivos y negativos capaces de subsidiar debates relevantes sobre la realidad, suponiendo que haya un cambio continuo en la percepción de las partes investigadas de la sociedad sobre el significado de la política y la democracia.

Palabras Clave: Democracia, movimientos sociales, coyuntura política, juventud, educación política.

\section{INTRODUÇÃo}

Em diferentes países do mundo, ao longo do início do século XXI, tem sido comum a realização de manifestações que buscam questionar o estado atual de realidades políticas, sociais e econômicas. Tais atos caracterizam-se por ações disseminadas pela internet, lideranças por vezes difusas, bem como pautas amplas que se disseminam a partir de algo considerado como estopim e a ausência na qualidade de organizadores centrais de grupos tradicionais, como partidos, sindicatos, etc.

Alguns casos tornaram-se mais emblemáticos, como o que se convencionou chamar de Primavera Árabe, que, a partir de dezembro de 2010, levou milhões de pessoas às ruas de países do norte da África e do Oriente Médio, que se mostravam contrárias aos governos e aos regimes vigentes. Também merece destaque a onda de manifestações resultante da crise econômica mundial de 2008, sobretudo em países da Europa, impactada diretamente pelos efeitos do debacle e cujos governos viram-se obrigados a tomar medidas severas de ajuste para a reorganização das contas públicas. Os casos de Itália, Espanha, Grécia, Irlanda e Portugal são relevantes.

Na América Latina não foi diferente. No Chile, desde 2012 o movimento estudantil insurgiu-se contra decisões oficiais atreladas às políticas de educação. $\mathrm{Na}$ Venezuela, a apertada vitória de Nicolás Maduro em 2013 não foi reconhecida por seu principal adversário, Henrique Capriles, fomentando uma série de protestos pelas ruas do país. No Paraguai, em 2012, após uma violenta reintegração de posse, uma crise resultou em manifestos e na queda do então presidente. Mais exemplos não faltam, e consequências e desdobramentos de tais movimentações não serão abordadas neste trabalho de forma profunda. O objetivo aqui é ilustrar e dar a dimensão do que tem ocorrido ao redor do mundo em tempos recentes.

Em 2013 foi a vez de o Brasil experimentar a eclosão de manifestações de insatisfação com o quadro vigente no país. Inicialmente compreendida como um movimento contrário ao reajuste do preço do transporte público na capital de São Paulo, a onda de protestos ganhou corpo em cerca de quatro centenas de cidades do país a partir de pautas difusas e, muitas vezes, regionalizadas. A nação experimentaria outros tantos movimentos dessa natureza ao longo dos anos seguintes, que resultaram na percepção do renascimento de manifestações de grupos de direita conservadora nas ruas, contribuindo para a abertura, por exemplo, de um processo de impeachment que derrubaria a presidente Dilma Rousseff(PT) do poder em 2016.

Nos últimos meses, em 2019, uma nova onda de protestos tomou conta da agenda da América do Sul. Movimentações na Venezuela em torno de uma tentativa de golpe de Estado contra um contestado governo e uma realidade social, econômica e política desgastada ilustra bem esse contexto. Na Bolívia, acusações de eleições fraudadas em torno de um quarto mandato presidencial para Evo Morales resultaram em renúncia do governante e acusações mútuas, por parte de grupos rivais, de golpes contra a democracia no país - em cerca de duzentos anos há quem afirme que o país passou por cerca de duas centenas de ocasiões dessa natureza. No Equador, insatisfação com o anúncio do fim dos subsídios aos combustíveis foi marcada pela intensidade de manifestações nas ruas. No Peru, utilizando-se de um dispositivo constitucional e objetivando o combate aos escândalos de corrupção que envolviam a construtora brasileira Odebrecht, o presidente dissolveu o Congresso e convocou eleições para janeiro de 2020. O Legislativo buscou reagir reconhecendo a vice-presidente como mandatária, mas ela renunciou ao posto. $\mathrm{Na}$ Argentina, a situação econômica levou milhares de cidadãos às ruas e o presidente tentou reverter a instabilidade lançando mão de políticas que contrariavam seu discurso eleitoral. Em novo pleito nacional, a oposição voltou ao poder. Por fim, no Chile, milhares de pessoas foram às ruas em seguidos movimentos contrários à realidade local, forçando o governo central a recuar em algumas decisões e a declarar, mais de uma vez, que o país estava em guerra. 
Diante dessa reorganização de forças continentais, dois discursos fizeram-se presentes de forma marcante: Estaria a democracia em risco no continente, ou esse tipo de fenômeno justamente consolida uma ideia cara à lógica democrática, a liberdade de expressão e de manifestação? Ademais, seria essa nova onda de movimentos capaz de chegar ao Brasil? O intuito deste texto não é responder a tais questões, mas, com base na relevância do instante vivido no continente, observar em que medida podemos dimensionar o apego dos brasileiros, medido de diferentes formas e em distintas realidades, à democracia. $\mathrm{O}$ que efetivamente caracteriza, em instante atual, a democracia brasileira de acordo com a percepção de seus cidadãos e de pesquisas que buscam medir a intensidade desse fenômeno no país?

Com base nessa última pergunta, a proposta deste trabalho está concentrada em revisitar resultados de levantamentos de opinião pública e indicadores de democracia que considerem a realidade do Brasil, com o intuito de verificar a atual situação da percepção da democracia no país. Ademais, a partir de um conjunto de dados quantitativos gerados no contato direto com jovens estudantes de escolas públicas das periferias de São Paulo, avaliar se ao longo dos últimos cinco anos houve algum tipo de mudança no perfil desse público em relação às percepções sobre a democracia no país. Parte-se da hipótese central de que em meia década, após as manifestações de 2013 e 2014, existe em curso um deslocamento gradual na forma de o brasileiro enxergar as instituições democráticas e notar aspectos basilares da democracia.

\section{Fundamentos TeóRicos}

Diferentes pensadores ofertaram suas versões para o conjunto de manifestações aqui citado. Tendo como ponto central uma profunda transformação na forma de a sociedade se comunicar e, consequentemente, conviver, Castells (2013) deixa clara a potência com que a internet e a rapidez das conexões constituem redes que se manifestam e se multiplicam de forma significativa em diferentes locais do mundo em torno de causas e pautas diversificadas. O objetivo do autor é investigar "os movimentos sociais da sociedade em rede, que, em última instância, farão as sociedades do século XXI, ao se engajarem em práticas conflitivas enraizadas nas contradições fundamentais de nosso mundo" (p. 9).

Especificamente sobre o que houve em 2013 no Brasil, em posfácio especial para a edição nacional, Castells observou que de forma inesperada e clamando por direitos e dignidade, a movimentação concentrou-se em criticar a "classe política". Nesse sentido, a "democracia teria sido sequestrada por profissionais da política", tendo se reduzido a um mercado de votos incapaz de perceber os novos rumos e demandas da sociedade.

A partir de tal percepção, o que exatamente conhecemos sobre o estado da democracia no Brasil sob a percepção dos brasileiros? Indicadores e pesquisas buscam compreender tal universo. O Índice de Confiança Social (ICS), medido desde 2009 pelo Ibope Inteligência, procura compreender o grau de confiança dos brasileiros em um conjunto bastante significativo de instituições. A essas organizações, em especial, o instituto dá o nome de "ICS-Instituições", que contava com uma média agregada de confiança de 58 pontos, em uma escala de 0 a 100, na primeira edição do levantamento em 2009. Interessante notar que entre 2013 e 2018 , anos em que o Brasil viveu o que se convencionou chamar de crise política aguda, essa média variou abaixo dos 50 pontos, atingindo um mínimo de 44 em 2018 e voltando aos 56 pontos em 2019.

Aqui parece possível servir-se de tais dados e dividir as instituições observadas no levantamento em cinco grandes conjuntos, numa análise especificamente destinada aos objetivos deste trabalho. O primeiro pode ser chamado de organizações "Hierarquizadas Públicas" e é formado por bombeiros, Forças Armadas, polícia e Poder Judiciário. O segundo será denominado de entidades "Privadas do Mercado", cujos componentes são os meios de comunicação, os bancos e as empresas. O terceiro foi batizado de organizações "Privadas Sociais", composto por igrejas, organizações não governamentais (ONGs) e sindicatos. O quarto foi chamado de instituições "Democráticas” e é composto por Governo Federal, presidente da República, eleições (e sistema eleitoral), Governo Municipal, Congresso Nacional e partidos políticos. Por fim, o quinto grupo foi chamado de "Gestão Pública" e é composto por escolas públicas e sistema de saúde. 
O Gráfico 1 mostra que os piores resultados ao longo de onze anos de levantamentos, assim como as oscilações mais expressivas, estão concentrados no grupo chamado de instituições "Democráticas”, sendo a queda no período de 2013 a 2018 explicada, principalmente, por um descrédito expressivo nas figuras do presidente da República e do Governo Federal. Importante salientar uma melhoria generalizada da confiança do brasileiro em 2019, capaz de colocar todos os grupos acima da média do período de onze anos. Importante ressaltar também que os resultados desta pesquisa, em especial, são capazes de captar instantes de insatisfação dos brasileiros com suas instituições, sobretudo no que diz respeito às organizações associadas à democracia, mas não conseguem ilustrar a acentuação do sentimento de polarização que vivemos em termos políticos no país.

Gráfico 1 - ICS Ibope organizado por grupos de instituições

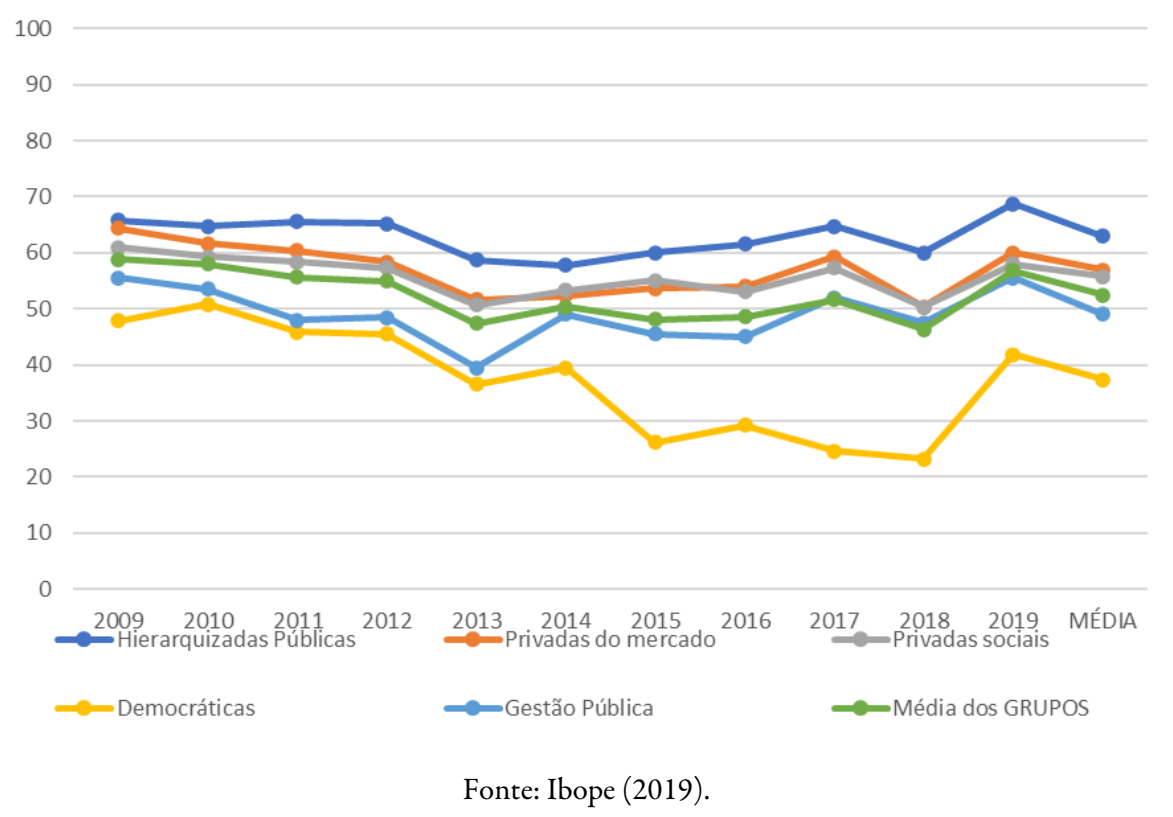

Diversos outros indicadores podem contribuir para a percepção desses resultados atrelados à relação do país com a democracia. Uma análise conjunta de três deles foi realizada por Dantas (2019). No Democracy Index, da publicação The Economist, em 2018 o Brasil era classificado como uma "democracia com falhas", e no continente estava acima da Colômbia e abaixo do Suriname, em nono lugar. O principal desafio estaria associado ao subgrupo que se convencionou chamar de "cultura política", onde o país atingiu apenas cinco pontos, sobre um total de dez. No IDD-Lat, indicador de Desenvolvimento Democrático calculado pela Fundação Konrad Adenauer para a América Latina, a posição do Brasil demonstrava problemas, uma vez que na versão mais recente, de 2016, era considerado de "baixo desenvolvimento" e atingia 4,367 pontos em 10 possíveis, ficando acima da Colômbia e abaixo de El Salvador. Um terceiro indicador relevante trazido pelo autor é o Latinobarómetro, calculado no Chile a partir de pesquisas de opinião pública em diferentes países do continente. No que se chama de Índice de Satisfação com a Democracia, em 2018 diferentes medidas foram testadas. No Brasil, o apoio à democracia atingia 34 pontos em 100 possíveis, e a percepção de que não fazia diferença viver numa ditadura ou num regime democrático chegava a 41 pontos. Para além desses dois pontos, diversas outras variáveis mostravam o Brasil nas piores posições no continente. Os resultados de tais indicadores sugerem que "a situação da democracia no Brasil se mostra fragilizada" (Dantas, 2019, p. 88).

Por sua vez, Bizarro e Coppedge (2017) buscam trabalhar com percepções sobre a democracia brasileira a partir do projeto "Variedades da Democracia" (V-Dem), um conjunto de cinco formulações acerca do fenômeno que, pautadas em definições distintas, indicam a situação de um país diante dos desafios e concepções de democracia. A partir da tentativa de fazer medidas em perspectivas históricas dessas diferentes 
dimensões do conceito, os autores concluem que "os avanços nos índices de democracia no Brasil a partir de vários componentes propostos pelo V-Dem têm magnitude desigual” (p. 37).

Em pesquisa denominada "Sonha Brasileiro da Política", realizada com jovens em 2014, buscando compreender o que cidadãos de 18 a 32 anos percebiam acerca da democracia e da realidade política do país a partir das manifestações de 2013, Pedreira (2015) concluiu que "novas práticas de participação política estão sendo testadas e colocando em xeque os limites impostos pelos sistemas políticos atuais" (p. 115). As renovações das percepções acerca da democracia e o desafio de buscar respostas às indignações colocavam os jovens no centro de um debate essencial. À ocasião do levantamento, mais de $90 \%$ sabiam das manifestações de 2013 e pouco menos de $20 \%$ haviam participado de alguma forma, o que em números absolutos era considerado um resultado expressivo e destacado pela autora.

Com objetivo semelhante, a Fundação Escola de Sociologia e Política de São Paulo (FESP-SP) foi às ruas da capital paulista para compreender a percepção dos jovens a respeito da democracia em instante de efervescência social no mês de agosto de 2014. Dantas e Almeida (2015) analisaram os resultados do levantamento e observaram que os jovens da capital, para além de uma participação intensa nos manifestos de 2013, "apenas reproduziram parte do que podemos entender como um traço de nossa cultura política", com destaque para o "afastamento em relação aos partidos, confiança mais acentuada em organizações de defesa, controle e justiça, desconfiança mais elevada nas organizações e movimentos sociais” (p. 80), algo semelhante ao que a análise aqui proposta mostrou sobre a pesquisa do Ibope.

Diante de tais resultados, análises e percepções, o objetivo aqui passa a ser compreender como jovens estudantes de ensino médio de escolas públicas da Grande São Paulo enxergam a política e se relacionam com valores democráticos. Com base nos resultados será possível verificar se em anos recentes existe alguma mudança em curso capaz de explicar a relação desse público com a política.

\section{Procedimentos Metodológicos}

Os dados aqui utilizados fazem parte de pesquisas anualmente realizadas pela Fundação Konrad Adenauer junto a jovens estudantes do ensino médio da rede pública na Grande São Paulo. Não se trata de um levantamento com amostra cientificamente elaborada, mas sim de um projeto de educação que atende jovens em escolas e projetos sociais que aceitam receber as atividades propostas, dentre elas a pesquisa.

Especificamente aqui serão utilizadas as informações de cinco anos, do período de 2015 a 2019. É a partir do ano mais distante que formulários foram aplicados entre os jovens antes de eles terem contato com cursos de iniciação política realizados em escolas e projetos sociais que atendem ao público de 15 a 18 anos. É esse o instante da percepção que melhor dialoga com os objetivos deste estudo, ou seja, a opinião dos estudantes ofertada em momento anterior às aulas. Para uma melhor compreensão do projeto da Fundação Konrad Adenauer, Dantas (2016) explica detalhadamente o funcionamento da atividade e traz uma análise de dados do ano de 2015.

O total de perguntas capaz de abranger todo o período, ou a maior parte dele, não é muito significativo, e o intuito aqui é promover uma análise descritiva desses dados, sem o emprego de sofisticações estatísticas, apresentando os resultados colhidos de acordo com o ano. Busca-se compreender se houve alguma mudança expressiva na forma de esses jovens entenderem e se relacionarem com a política no período. Serão utilizadas aqui apenas as respostas dos jovens regularmente matriculados no Ensino Médio público, com idades entre 16 e 18 anos no ato da resposta. Esse recorte oferece um total de 368 questionários em 2015, 499 em 2016, 652 em 2017, 648 em 2018 e 475 em 2019 - nesse último ano os resultados são parciais. Na Tabela 1 é possível apreender o perfil dos alunos e alunas que participaram da pesquisa nos cinco anos destacados. 
Tabela 1 - Perfil dos jovens pesquisados nos cursos de Iniciação Política

\begin{tabular}{|l|l|l|l|l|l|}
\hline Ano & Mulheres & Homens & $\begin{array}{l}\text { Idade } \\
\text { média } \\
\text { (anos) }\end{array}$ & $\begin{array}{l}\text { Ano } \\
\text { médio (no } \\
\text { Ensino } \\
\text { Médio) }\end{array}$ & Estudantes \\
\hline 2015 & $58 \%$ & $42 \%$ & 16,7 & 2,6 & 368 \\
\hline 2016 & $58 \%$ & $42 \%$ & 16,7 & 2,4 & 499 \\
\hline 2017 & $58 \%$ & $42 \%$ & 16,7 & 2,6 & 652 \\
\hline 2018 & $54 \%$ & $46 \%$ & 16,5 & 2,5 & 648 \\
\hline 2019 & $54 \%$ & $46 \%$ & 16,5 & 2,5 & 475 \\
\hline
\end{tabular}

Fonte: Fundação Konrad Adenauer.

O perfil dos alunos pesquisados demonstra homogeneidade entre os anos com relação à distribuição de gênero, média de idade e média dos anos do ensino médio onde o grupo estava no instante da pesquisa. Assim, eventuais alterações na percepção dos jovens não parecem ser impactadas pelo perfil daqueles que responderam os questionários.

\section{ANÁLISE DE DADOS}

Feitas as considerações sobre os métodos e a dimensão da pesquisa, a partir de agora serão apresentados os resultados, de acordo com a ordem das perguntas apresentadas nos questionários aos estudantes. Primeiramente, o intuito era compreender quais os canais mais utilizados para a busca regular de informações sobre política. Uma lista com 11 itens era apresentada em 2019, mas na Tabela 2 serão mostradas apenas as opções que fazem sentido para a análise aqui proposta, sendo que na última coluna é mostrada a média de todos os 11 canais apresentados. A exceção é 2015, que tinha um conjunto diferente de opções e por isso não será trazido.

Tabela 2 - Fontes utilizadas para a obtenção de informações políticas por estudantes

\begin{tabular}{|l|l|l|l|l|l|}
\hline Ano & TV & $\begin{array}{l}\text { Internet } \\
\text { (Sites) }\end{array}$ & $\begin{array}{l}\text { Redes } \\
\text { Sociais }\end{array}$ & Escola & $\begin{array}{l}\text { Média } \\
\text { dos } \\
\text { meios } \\
\text { (todos) }\end{array}$ \\
\hline 2015 & $91 \%$ & $50 \%$ & $55 \%$ & $47 \%$ & --- \\
\hline 2016 & $86 \%$ & $51 \%$ & $55 \%$ & $40 \%$ & $30 \%$ \\
\hline 2017 & $84 \%$ & $52 \%$ & $61 \%$ & $38 \%$ & $30 \%$ \\
\hline 2018 & $81 \%$ & $58 \%$ & $64 \%$ & $38 \%$ & $32 \%$ \\
\hline 2019 & $82 \%$ & $61 \%$ & $62 \%$ & $37 \%$ & $32 \%$ \\
\hline
\end{tabular}

Fonte: Fundação Konrad Adenauer.

Interessante notar alguns fenômenos que já fazem parte do debate público acerca de comunicação na sociedade. Primeiramente, não existe uma mudança expressiva na média de uso dos canais disponibilizados aos jovens de maneira uniforme desde 2016, ou seja, não é possível dizer que exista alteração significativa na forma de esses estudantes diversificarem suas fontes de informação política. Entretanto, em relação aos canais trazidos na Tabela 2, nota-se que a TV perde espaço ao longo do período, deslocando-se da casa dos 90 pontos para os 80, o que em meia década parece um fenômeno bastante representativo. Em contrapartida, os sites caminham da barreira dos 50 para os 60 pontos, movimento semelhante ao observado nas redes sociais e capaz de representar uma tendência geracional relevante atrelada à acentuação de instrumentos virtuais de informação. A escola também perde espaço significativo, o que em termos de políticas públicas de educação 
para a consolidação da democracia é algo preocupante. Para além da exigência de conteúdos dessa natureza em documentos oficiais, como por exemplo a Base Nacional Comum Curricular recentemente aprovada, é de Norberto Bobbio (1986) a percepção de que a "educação política é a promessa não cumprida da democracia", o que oferta a percepção de que problemas são enfrentados no campo político-democrático quando a escola não se consolida como o espaço para a disseminação de informações e formações políticas.

Em um segundo conjunto de questóes o objetivo era compreender a relação do estudante com alguns elementos da democracia representativa. Perguntas acerca da obtenção do título de eleitor, das percepções sobre o voto e da simpatia pelos partidos políticos foram apresentadas. Na Tabela 3 é possível verificar os percentuais de algumas respostas.

Tabela 3 - Posição dos estudantes sobre a política

\begin{tabular}{|l|l|l|l|l|l|}
\hline Ano & $\begin{array}{l}\text { Obtenção } \\
\text { do título } \\
\text { de eleitor } \\
\text { com } \\
\begin{array}{l}\text { menos } \\
\text { de } 18 \\
\text { anos }\end{array}\end{array}$ & $\begin{array}{l}\text { O voto é } \\
\text { mais um } \\
\text { direito (do } \\
\text { que uma } \\
\text { obrigação) }\end{array}$ & $\begin{array}{l}\text { Declara } \\
\text { gostar de } \\
\text { política }\end{array}$ & $\begin{array}{l}\text { Não se } \\
\text { vê } \\
\text { candidato } \\
\text { ou } \\
\text { filiado a } \\
\text { partido }\end{array}$ & $\begin{array}{l}\text { Nấo } \\
\text { simpatiza } \\
\text { com } \\
\text { nenhum } \\
\text { partido }\end{array}$ \\
\hline 2015 & $45 \%$ & $73 \%$ & --- & --- & $88 \%$ \\
\hline 2016 & $49 \%$ & $67 \%$ & $19 \%$ & $86 \%$ & $90 \%$ \\
\hline 2017 & $51 \%$ & $80 \%$ & $18 \%$ & $85 \%$ & $91 \%$ \\
\hline 2018 & $49 \%$ & $79 \%$ & $20 \%$ & $85 \%$ & $85 \%$ \\
\hline 2019 & $51 \%$ & $81 \%$ & $25 \%$ & $89 \%$ & $83 \%$ \\
\hline
\end{tabular}

Fonte: Fundação Konrad Adenauer.

Alguns dados chamam a atenção de maneira bastante discreta no que diz respeito às movimentações verificadas no período. A obtenção do título com menos de 18 anos divide claramente em metades praticamente iguais os estudantes nesses cinco anos. Sem grandes movimentações, a partir de 2017, destacase também a percepção de que o voto é predominantemente um direito e não uma obrigação, com aumento no triênio mais recente. A despeito dessa relevância, a imensa maioria dos jovens, no futuro, não se vê filiada a legendas, tampouco envolvida em candidaturas no período entre 2016 e 2019 . Tal posição se reflete nos partidos, que não contam com a simpatia do público pesquisado em percentuais bastante elevados. A queda, a partir de 2018, na antipatia às legendas, ocorre declaradamente graças ao aparecimento do Partido Social Liberal (PSL), associado à figura do presidente Jair Bolsonaro. Por fim, importante destacar um crescimento discreto no percentual de jovens que, espontaneamente, afirma gostar de política. A pergunta era formulada da seguinte maneira: "Em relação à política, você diria que: Não gosta e não precisa dela; não gosta, mas sabe que ela é importante para sua vida, ou gosta de política?”. Inicialmente, menos de um em cada cinco estudantes afirmava gostar do tema, algo que em 2019 atinge, de forma bastante relevante, a razão de um para cada quatro jovens.

No conjunto de dados seguintes, apresentados na Tabela 4, o objetivo era compreender em que medida o jovem atuava em ações disponibilizadas nos questionários e típicas de alguns segmentos da sociedade. Aqui, o intuito era entender a participação recente em grêmios escolares e manifestações de diferentes tipos. 
Tabela 4 - Participação política ativa dos jovens em canais apresentados

\begin{tabular}{|l|l|l|l|l|}
\hline Ano & $\begin{array}{l}\text { Participa } \\
\text { do Grêmio } \\
\text { Escolar }\end{array}$ & $\begin{array}{l}\text { Já foi a } \\
\text { movimento } \\
\text { de rua }\end{array}$ & $\begin{array}{l}\text { Já fez } \\
\text { manifestação } \\
\text { virtual }\end{array}$ & $\begin{array}{l}\text { Participou } \\
\text { de } \\
\text { ocupação } \\
\text { de escola }\end{array}$ \\
\hline 2015 & $19 \%$ & --- & --- & --- \\
\hline 2016 & $17 \%$ & $22 \%$ & $15 \%$ & --- \\
\hline 2017 & $17 \%$ & $19 \%$ & $15 \%$ & $5 \%$ \\
\hline 2018 & $16 \%$ & $18 \%$ & $21 \%$ & $5 \%$ \\
\hline 2019 & $14 \%$ & $15 \%$ & $24 \%$ & $6 \%$ \\
\hline
\end{tabular}

Fonte: Fundação Konrad Adenauer.

Os resultados das variáveis aqui testadas trazem algumas tendências discretas, mas relevantes para os fenômenos aqui percebidos. A participação ativa nos grêmios escolares, objeto de lei específica que trata da obrigatoriedade do instrumento nas escolas paulistas e de esforços específicos da Secretaria Estadual de Educação de São Paulo, demonstrou queda no período abordado. Em relação às manifestações, as ruas cedem nítido espaço para a internet, havendo o que se poderia chamar de uma inversão da dimensão da atuação dos estudantes nesses canais. Assim, se por um lado o ritmo de movimentos de rua no Brasil não parecer estar, em 2019, tão vivo quanto em anos anteriores, sobretudo até 2016, o ambiente virtual ganha representatividade. Por fim, as ocupações de escolas, bastante comuns e vivenciadas em São Paulo com intensidade em 2015, não atingem percentual significativo de respondentes.

No último bloco de perguntas os jovens eram apresentados a um conjunto de afirmações. Em relação a elas podiam adotar quatro posições: Concordar totalmente, concordar em partes, discordar em partes e discordar totalmente. Para visualizar os resultados, cada resposta recebeu uma pontuação diferente, sendo 3 para concordar totalmente, 2 para concordar em partes, 1 para discordar em partes e 0 para discordar totalmente. A partir das médias das respostas chega-se a um valor que, dividido por 3, oferece o percentual médio de concordância com a sentença, ou o que se pode chamar de índice de concordância. Quanto mais perto de 3, maior a concordância com a sentença. As seis frases que estavam presentes nos cinco anos da pesquisa foram:

- Todos os políticos são corruptos;

- A corrupção é o maior problema do Brasil;

- A educação política deve estar presente nas escolas;

- O voto tem poder de transformação na sociedade;

- O voto obrigatório desafia princípios da democracia;

- Depredar empresas é uma forma legítima de manifestação.

$\mathrm{Na}$ Tabela 5 é possível conhecer o princípio norteador das frases apresentadas aos estudantes e verificar o grau de respostas por ano, buscando compreender algumas tendências no comportamento dos estudantes. 
Tabela 5 - Graus de concordância dos estudantes com sentenças apresentadas

\begin{tabular}{|l|l|l|l|l|l|l|}
\hline Ano & $\begin{array}{l}\text { Todos os } \\
\text { políticos } \\
\text { São } \\
\text { Corruptos }\end{array}$ & $\begin{array}{l}\text { A } \\
\text { corrupção } \\
\text { é o } \\
\text { maior } \\
\text { problema } \\
\text { do Brasil }\end{array}$ & $\begin{array}{l}\text { A } \\
\text { educação } \\
\text { política } \\
\text { deve } \\
\text { estar } \\
\text { presente } \\
\text { nas } \\
\text { escolas }\end{array}$ & $\begin{array}{l}\text { O voto tem } \\
\text { poder de } \\
\text { transformação } \\
\text { na sociedade }\end{array}$ & $\begin{array}{l}\text { O voto } \\
\text { obrigatório } \\
\text { desafia } \\
\text { principios } \\
\text { da } \\
\text { democracia }\end{array}$ & $\begin{array}{l}\text { Depredar } \\
\text { empresas é } \\
\text { uma forma } \\
\text { legitima de } \\
\text { manifestação }\end{array}$ \\
\hline 2015 & $62 \%$ & $79 \%$ & $84 \%$ & $81 \%$ & $66 \%$ & $16 \%$ \\
\hline 2016 & $54 \%$ & $77 \%$ & $84 \%$ & $81 \%$ & $61 \%$ & $11 \%$ \\
\hline 2017 & $56 \%$ & $78 \%$ & $87 \%$ & $83 \%$ & $62 \%$ & $12 \%$ \\
\hline 2018 & $52 \%$ & $74 \%$ & $86 \%$ & $84 \%$ & $65 \%$ & $10 \%$ \\
\hline 2019 & $51 \%$ & $74 \%$ & $86 \%$ & $86 \%$ & $59 \%$ & $9 \%$ \\
\hline
\end{tabular}

Fonte: Fundação Konrad Adenauer.

Consideremos para os fins dessa análise que, quanto mais perto de $0 \%$, mais se pode falar em discordância plena, perto de $33 \%$ pode-se falar em discordância relativa, em $67 \%$ temos concordância relativa e perto de $100 \%$, concordância total. Duas sentenças muito associadas à democracia ultrapassam os $80 \%$ em todos os anos da pesquisa. Estariam, assim, no caminho entre a concordância relativa e a absoluta. Trata-se da percepção do jovem de que a educação política deve estar presente nas escolas e de que o voto tem poder de transformação. Tais percepções servem de base para uma lógica de respeito à democracia.

O mesmo não parece possível de ser dito acerca do voto compulsório. Aos olhos dos jovens parece ser esta uma característica que desafia princípios da democracia, restando saber aqui o que exatamente os estudantes entendem pelo fenômeno. A despeito de tal condição, aproxima-se da lógica de "concordar em partes" o resultado da percepção dos estudantes sobre essa afirmação.

Em ritmo de queda, temos a percepção de que todos os políticos são corruptos. O resultado que flerta com a ideia de concordância em partes recua no sentido da neutralidade, que seria simbolizado pelos $50 \%$ - algo do tipo "nem concorda e nem discorda". O resultado deve ser visto como positivo, uma vez que relativiza uma sensação do senso comum de que todos os políticos não prestam - o perigo aqui está, no entanto, em observar a média sem considerar o desvio padrão das respostas, uma vez que os $50 \%$ podem simbolizar a divisão exata do universo em respostas extremas. Ademais, por se tratar de uma média das respostas é fato que existe aqui, de forma bastante presente, a sensação negativa sobre a "classe política", mas também existe quem arrefeça esse sentimento.

Com relação ao fenômeno da corrupção, outra sentença merece destaque e chama a atenção o fato de que nesse caso o resultado se situa em grau de concordância entre o relativo e o absoluto. Aqui, o que se tem é a percepção sobre a corrupção como o maior problema do Brasil. A pauta dos meios de comunicação, os escândalos que têm marcado a história recente do país e os discursos inflamados de políticos contra a corrupção podem contribuir para o adensamento desse sentimento, cujos resultados situam-se acima dos 70 pontos percentuais em todo o período analisado.

Por fim, importante destacar que a depredação de empresas como gestos legítimos de manifestação demonstra queda relevante no período analisado. De um grau baixo de concordância, na casa dos $16 \% \mathrm{em}$ 2015, o que seria o ponto central entre discordar totalmente e discordar em partes, a percepção do fenômeno cai para menos de $10 \%$ em 2019. 


\section{Discussão}

Os resultados trazidos pela análise das frequências das perguntas feitas aos jovens estudantes do ensino médio da Grande São Paulo, divididas de acordo com o ano de aplicação da pesquisa, mostram alguns traços relevantes sobre a visão desse público acerca de fenômenos democráticos. Alguns sugerem distanciamento, enquanto outros apontam para a valorização de instrumentos bastante relevantes. Interessante, nesses casos, notar como muito do que foi apresentado em termos mais teóricos, bem como nos resultados de algumas pesquisas mais abrangentes, guarda relação com aspectos percebidos nos levantamentos feitos ao longo dos cinco anos mais recentes das atividades de Iniciação Política da Fundação Konrad Adenauer nas periferias da Grande São Paulo.

Assim, merece atenção aqui a capacidade positiva de os jovens valorizarem o voto por meio da percepção de que se trata, predominantemente, de um direito, bem como de um instrumento democrático com alto poder de transformação. A despeito de tal posição favorável aos fins da democracia, a declaração de interesse pela procura do título eleitoral com menos de 18 anos divide igualmente o grupo, com $51 \%$ no levantamento de 2019 afirmando interesse pelo voto com menos de 18 anos. $\mathrm{O}$ aspecto benéfico desse número é que tal percentual se encontra muito acima dos cerca de $21 \%$ de jovens dessa faixa etária que obtiveram o documento para as eleições de 2018 de acordo com o Tribunal Superior Eleitoral. Em contrapartida, negativamente é possível verificar que o percentual associado à metade dos respondentes ainda está aquém da taxa média de comparecimento dos brasileiros às urnas quando o voto se torna compulsório, na casa dos 80 pontos percentuais. Ademais, é relevante destacar que declarar um desejo em um questionário é diferente de efetivar tal objetivo, ou seja, obter o título de eleitor em um cartório eleitoral.

Pesa também positivamente nesse conjunto de percepções da pesquisa da Fundação Konrad Adenauer a ideia de que é crescente o percentual de estudantes que dizem "gostar de política". O total de $25 \%$ obtido mais recentemente é complementado por um aumento em alguns canais virtuais de participação política e na busca por informação no ambiente associado à internet, o que caracteriza um perfil geracional cada vez mais claro e capaz de movimentar a política em universo distinto daquele que tradicionalmente levou as pessoas às ruas e (ou) colocou-as diante da TV. Assim, enquanto menos jovens vão às ruas no período, o índice daqueles que participaram de alguma manifestação virtual subiu para 24\% em 2019, o maior valor registrado na Tabela 4, que buscava entender características atuais da atuação dos estudantes. Pontos a serem lamentados aqui estão associados à redução do espaço de participação dos jovens nos grêmios estudantis e nos movimentos de rua, mas importante salientar a queda nos graus de concordância com questões relativas à depredação de empresas como gesto legítimo de manifestação. Assim, tudo indica que efetivamente o ambiente virtual se consolida de maneira mais consistente como espaço político dessa juventude, algo destacado de maneira bastante intensa por Castells (2013) e Pedreira (2015). Tal fenômeno é percebido nitidamente, a despeito da qualidade daquilo que se consome, nos canais utilizados para a busca de informações políticas. Enquanto a TV, tradicional por seus telejornais, perde espaço próximo de dez pontos percentuais em meia década, são as redes sociais e a internet (e seus sites) que ampliam a participação ao longo dos cinco anos observados.

Ainda no campo dos aspectos positivos, importante salientar a percepção de como os estudantes concordam com a ideia de que conteúdos de educação política devem estar presentes nas escolas, algo que Pedreira (2015) e Dantas (2016) já haviam destacado em seus textos. A percepção negativa, nesse caso, fica por conta de como a escola passa a ocupar espaço decrescente no período, quando os jovens tratam de observar as fontes de informação utilizadas por eles na obtenção de informações políticas. O debate sobre a educação política no Brasil tem tomado importante espaço no meio acadêmico, sendo objeto, para além de muitos artigos produzidos em diferentes periódicos, de três publicações de volumes específicos de revistas. Duas edições de Cadernos Adenauer, uma em 2010 (volume 3) e outra em 2016 (volume 1), bem como da revista E-Legis, do programa de pós-graduação do Centro de Formação da Câmara dos Deputados, em 2011. 
Entre as obras associadas à percepção de jovens sobre ações dessa natureza, destaque para o trabalho de Cosson (2019). O autor avalia o programa Estágio-Visita da Câmara dos Deputados, compreendendo-o como instrumento de letramento político destinado a universitários. A atividade, segundo ele, amplia a visão dos estudantes sobre o parlamento, a despeito de por vezes não arrefecer uma visão crítica e ácida sobre a temática democrática. Bressanelli e Cosson (2016), por sua vez, buscaram compreender como a atividade denominada Estágio Participação aproximava o Poder Legislativo e a sociedade. Os autores perceberam que a iniciativa fortalecia a ideia da importância de uma formação política consciente para uma atuação cidadã mais consistente dos jovens.

Já no âmbito dos estados, e igualmente preocupados em compreender o impacto de atividades de educação política realizadas por parlamentos, Kelles e Marques (2010), bem como Fuks e Casalecchi (2016), avaliaram o Parlamento Jovem de Minas Gerais notando a relevância e o caráter educativo da atividade na visão dos estudantes. Em Santa Catarina, Silvestre (2016) chegou a conclusão semelhante sobre o Parlamento Jovem daquele estado. Municipalmente, é o estudo de Nascimento, Silva e Seino (2016) que indica o impacto de ações de educação política sobre estudantes de Araraquara, interior de São Paulo, mostrando o reconhecimento desses cidadãos sobre a importância de conteúdos dessa natureza. Mesmo caminho segue Forlini (2015) em pesquisa qualitativa com jovens do ensino médio dessa mesma cidade. Ademais, Dantas e Lamari (2019) apontam a percepção dos jovens sobre a educação política em Itapevi (SP) e São Paulo (SP), e notam que impactados por ações formais desse tipo reconhecem a relevância dos conteúdos trabalhados para suas realidades enquanto cidadãos e estudantes. Por fim, Dantas (2016) faz o mesmo com o trabalho dos cursos de Iniciação Política da Fundação Konrad Adenauer, utilizados aqui como fonte dos dados quantitativos dos questionários aplicados, mostrando o valor dado pelos estudantes aos cursos ministrados em escolas e organizações sociais.

Esses exemplos são relevantes para marcar os esforços de avaliação sobre parte das ações desenvolvidas junto a jovens estudantes no universo da educação política, mas resta saber como vencer alguns aspectos negativos apresentados em relação à lógica da democracia representativa mais formal, por exemplo, o caráter compulsório do voto é visto como capaz de desafiar princípios democráticos. O que os respondentes entendem aqui por democracia? Seria apenas a liberdade de praticar ou não algo? E nesse caso estão tratando do voto? Outro ponto é o desapego à lógica dos partidos políticos, entendidos aqui a partir de uma antipatia que supera os 80 pontos percentuais em todo o período analisado em relação às legendas. O ponto positivo seria a redução do fenômeno por meio do reconhecimento do PSL como uma agremiação que em 2018 teria sido capaz de atrair alguma afinidade. A despeito do que isso de fato possa representar, o fenômeno despertou o olhar dos jovens para as legendas. O desafio aqui é lembrar que tal organização surgiu com força no cenário nacional a partir da filiação de um único agente, que venceu o pleito presidencial de 2018 e a já a abandonou. Nesse caso, Jair Bolsonaro seria uma figura comum às tradições personalistas da política nacional, e não exatamente um agente capaz de fortalecer o sentimento de proximidade com os partidos políticos por parte de parcelas da sociedade - pelo contrário, pois recentemente declarou que está criando seu próprio partido, já que abandonou o PSL. Fortalece esse distanciamento das legendas e à política eleitoral o sentimento de que os estudantes não se veem como candidatos ou filiados. O que os distancia tanto dos partidos políticos? E das eleições em geral? Claro que uma pergunta desse tipo pode gerar uma surpresa, e respostas esperadas podem caminhar no sentido de negar futuras candidaturas, sendo a faixa etária dos 16 aos 18 anos um momento atípico para esse tipo de cálculo. Os jovens sequer se enxergam, no futuro, filiados a uma legenda, o que em uma democracia representativa onde os partidos funcionam bem poderia ser algo bastante natural na realidade da juventude. 


\section{Considerações Finais}

Este artigo partiu da hipótese central de que diante de movimentações sociais na última década em diferentes lugares do mundo e especificamente no Brasil a partir de 2013, em meia década, após as manifestações de 2013 e 2014, existiria em curso um deslocamento gradual na forma de o brasileiro enxergar as instituições democráticas e notar aspectos basilares da democracia. As tentativas de respostas a essa percepção estariam associadas à busca por compreensão do quanto o país estaria às vésperas de assistir novos movimentos da sociedade, tendo em vista o ocorrido em meses recentes no continente sul-americano. Para tanto, foram utilizadas diferentes pesquisas associadas às percepções dos brasileiros sobre a política e a democracia, com ênfase maior no posicionamento de jovens estudantes de escolas de ensino médio da Grande São Paulo entre 2015 e 2019.

Os resultados permitem debates relevantes sobre uma série de fenômenos políticos, mas não há indícios concretos de transformações profundas na visão dos sujeitos que levariam a um aumento na descrença nas instituições. Pelo contrário: A eleição de Jair Bolsonaro, a despeito de um discurso ácido e intenso em termos ideológicos, atenuou a descrença dos brasileiros, de acordo com o Ibope, em grupos de instituições afeitas à lógica da democracia. Outras pesquisas mostram afastamento dos brasileiros em relação a aspectos essenciais do universo democrático, mas não a ponto de sugerirem uma ruptura ou intensidade de desapegos e fenômenos semelhantes.

Por fim, quando os dados das pesquisas com jovens realizadas pela Fundação Konrad Adenauer foram trazidos para o debate, transformações na forma como o público se informa e se manifesta, intensificando o papel da internet, aparecem como as questões mais marcantes. Se por um lado isso não sugere grandes mudanças, por outro é necessário salientar que a velocidade do universo virtual pode sugerir um elemento de incerteza mais intenso.

Com relação a outros pontos atrelados ao olhar sobre os estudantes, é necessário considerar o apego a pontos essenciais como a educação política, o voto como direito e seu poder de transformar a realidade, algo que contrataste com instrumentos formais de participação como o apego aos partidos, a possibilidade de se candidatar um dia e o caráter compulsório do voto. Tais realidades, assim como os demais pontos destacados, não sugerem a existência de movimentos que tendam à ruptura de elementos centrais da democracia.

\section{REFERÊNCIAS}

Bizarro, Fernando, \& Coppedge, Michael. (2017). Variedades da Democracia no Brasil. Opinião Pública, Campinas, 23(1), 1-42.

Bobbio, Norberto. (1986). O futuro da democracia - uma defesa das regras do jogo. Rio de Janeiro: Paz e Terra.

Bressanelli, Renata, \& Cosson, Rildo. (2016). Letramento Político, juventude e mídias sociais: \#EstágioParticipação. Cadernos da Escola do Legislativo. Belo Horizonte: Assembleia Legislativa de Minas Gerais, v. 8, n. 29.

Castells, Manuel. (2013). Redes de indignação e esperança. Rio de Janeiro: Zahar.

Cosson, Rildo. (2019). Letramento Político - a perspectiva do Legislativo. Brasília: Câmara dos Deputados.

Dantas, Humberto, \& Almeida, Rodrigo. (2015). Como a juventude se relaciona com a democracia: compreensões com base em pesquisas. Cadernos Adenauer, Rio de Janeiro, ano XVI, n. 1.

Dantas, Humberto. (2019). A democracia brasileira na atualidade: experiências e amadurecimentos. In. Democracia, Diálogo e Cooperação - a Fundação Konrad Adenauer no Brasil - 50 anos. Rio de Janeiro, Fundação Konrad Adenauer. 73-90.

Dantas, Humberto. (2016). Educação política nas periferias da Grande São Paulo. Cadernos Adenauer, Rio de Janeiro, ano XVII, n. 1. 
Dantas, Humberto, \& Lamari, Roberto Eduardo. (2019). A relação de jovens do Ensino Médio com a política: análises a partir de grupos de estudantes de escolas públicas de São Paulo-SP e Itapevi-SP. Revista do Legislativo Paranaense, 1(2), 1-20.

Forlini, Danilo. (2015). Construindo caminhos para a educação política: a percepção dos alunos como um meio para pensar a educação para a Democracia. Dissertação (Mestrado em Educação Escolar) - Universidade Estadual Paulista "Júlio de Mesquita Filho, Faculdade de Ciências e Letras, Araraquara.

Fuks, Mario, \& Casalecchi, Gabriel. (2016). Formando cidadãos democráticos - considerações sobre os efeitos do Parlamento Jovem mineiro. Cadernos Adenauer, Rio de Janeiro, ano XVII, n. 1.

Ibope. Índice de Confiança Social 2019. Relatório de Pesquisa. São Paulo, Ibope Inteligência. Recupero de: https://www.ibopeinteligencia.com/arquivos/JOB\%2019_0844_ICS_INDICE_CONFIANCA_SOCIA L_2019\%20-\%20Apresenta\%C3\%A7\%C3\%A3o\%20(final).pdf.

Kelles, Eugênia, \& Marques, Maria Elizabeth. (2010). Parlamento Jovem: uma experiência inovadora em Minas. Cadernos Adenauer, Rio de Janeiro, ano XI, n. 3.

Nascimento, Alessandra, Silva, Bruno, \& Seino, Eduardo. (2016). Educação para a cidadania: o projeto Parlamento Jovem em Araraquara-SP. Cadernos Adenauer, Rio de Janeiro, ano XVII, n. 1.

Pedreira, Beatriz. (2015). Sonhos da juventude brasileira: a política além do voto. Cadernos Adenauer, Rio de Janeiro, ano XVI, n. 1, 101-120.

Silvestre, Melissa. (2016). Das ideias à concretude - a experiência do Programa Parlamento Jovem catarinense na última década. Cadernos Adenauer, Rio de Janeiro, ano XVII, n. 1.

\section{BY-NC-ND}

